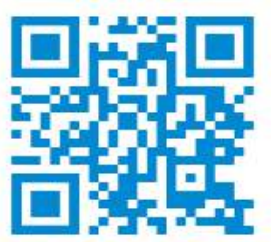

Scan to know paper details and author's profile

\title{
Oral Health Promotion in Children With Microcephaly After Social Isolation by Covid-19 Experience Report
}

Dara Vitória Pereira Lopes Silva, Felipe Barros Castro, Fernanda de Carvalho Reis, Mayana Narde Souza, Rafael Almeida Monteiro, Taylline das Mercês Gonçalves, Francisco Xavier Paranhos Coelho Simões \& Maria da Conceição Andrade de Freitas

\section{ABSTRACT}

The purpose of this study was to report extracurricular activities performed by professors and students of the Dentistry course at the State University of Southwest Bahia. Their goal was to promote oral health to microcephaly patients and their parents, after the period of social isolation due to the COVID-19 pandemic. In this context, a university extracurricular activity, more than ever, must assume its social responsibility, establishing new paths for public health care and regarding these actions correlating the academic community and society.

Keywords: microcephaly; public health; dentistry ; universities.

Classification: NLMC CODE: WU 113

Language: English 



\title{
Oral Health Promotion in Children With Microcephaly After Social Isolation by Covid-19: Experience Report
}

\author{
Dara Vitória Pereira Lopes Silva ${ }^{\alpha}$, Felipe Barros Castro ${ }^{\sigma}$, Fernanda de Carvalho Reis ${ }^{\rho}$, \\ Mayana Narde Souza ${ }^{\omega}$, Rafael Almeida Monteiro* ${ }^{*}$ Taylline das Mercês Gonçalves ${ }^{\S}$, \\ Francisco Xavier Paranhos Coelho Simões ${ }^{x} \&$ Maria da Conceição Andrade de Freitas ${ }^{v}$
}

\section{ABSTRACT}

The purpose of this study was to report extracurricular activities performed by professors and students of the Dentistry course at the State University of Southwest Bahia. Their goal was to promote oral health to microcephaly patients and their parents, after the period of social isolation due to the COVID-19 pandemic. In this context, a university extracurricular activity, more than ever, must assume its social responsibility, establishing new paths for public health care and regarding these actions correlating the academic community and society.

Keywords: microcephaly; public health; dentistry; universities.

\section{INTRODUCTION}

Throughout the history of undergraduate studies in Brazil, extracurricular activities were characterized by their assistance to local communities, often conducted towards low income citizens. However, it is commonly mistaken to assume that service is a one-way street. Extracurricular activities provide a dialogue between the university and society, where both environments teach and learn from each other, making the university not the only place where knowledge is shared. Consequently, professors and students must understand that in order to achieve a high quality education, the implementation of extracurriculars in their academic curriculum is extremely necessary. The Ministry of Education in Brazil included these activities in university courses through resolution number 7 in 2018. The National Education Plan was implemented for better qualification of future professionals. This legal provision establishes that extracurricular activities - EA must comprise at least $10 \%$ of the total student curricular workload of undergraduate courses for the composition of curriculum.

During the period of social isolation due to high transmissibility of the new Coronavirus, universities had the relevant mission to supply technological, educational, cultural advances and community innovation with a role of social responsibility for their EA. In Brazil, universities' extracurricular practices were encouraged by promoting an educational, critical and ethical process through the implementation of Information and Communication Technologies in order to provide services in situations where it was necessary to overcome geographic, temporal, social and cultural barriers. In the scientific literature, an integrative review highlights studies that emphasize the use of teledentistry as a global reality, being an important tool to aid dental care, especially for the most vulnerable populations (TEIXEIRA et al, 2018), such as children diagnosed with microcephaly.

Currently, there is a lack of oral health education programs aimed at children with microcephaly, including a protocol for preventive dental care. Studies show parents' reports about the complexity of oral hygiene habits in their children's routine. Added to these factors, diet and continuous use of medications increase the incidence of oral pathologies. Additionally, there is an experience report of oral health promotion activities developed by professors and students of the Dentistry course to children with microcephaly after the social isolation resulting 
from the COVID-19 health crisis, based on the principles of universality, equity and integrality.

\section{METHODS}

This is an observational study with a qualitative descriptive approach of a report of experience by undergraduate students and professors of the Dentistry course at the State University of Southwest Bahia (UESB). Since april 2017, the project named "Alvaro Marques Dental Center-Microcephaly" registered in UESB attendance services has been developed to promote oral health and dental care for individuals with microcephaly born in Jequié or nearby cities of Bahia, Brazil.

In COVID-19 pandemic period, oral health promotion activities were created by the academic team in a virtual format for individuals with microcephaly through their parents. The benefited public included 26 children diagnosed with microcephaly and/or congenital anomalies and syndromes registered in the project. Undergraduate students of the UESB Dentistry course under the guidance of professors, produced educational cards and videos about oral hygiene and dental development from July 2020 to November 2021. These materials were sent weekly to families through WhatsApp. There was also the participation of professors and students of the Nursing course, in 2021, with production of virtual cards/videos of health care for preventing COVID-19 contamination. They also promoted a virtual meeting with microcephaly children's parents, approaching mental health.

Nowadays, with the flexibility of physical and social isolation, it was possible, in October 2021, to return to dental practices in the Dentistry Module at UESB. These clinical activities are composed by collaborating professors of various Dentistry specialties such as Pediatric Dentistry, Periodontics, Maxillofacial Surgery and Endodontics. These professors are responsible for supervising the students according to the dental treatment plan and necessity of children with microcephaly. Also, educational cards and/or videos on oral hygiene were sent online once a week, and an academic team was available to answer possible doubts and additional information by Whatsapp.

\section{EXPERIENCE REPORT}

University extracurricular activities concept emerges when the processes of public education begin to be discussed, at which time professors and students dialogue about the role of the university in social problems and inequalities. In the conception and practice of extracurricular activities guidelines in graduation, the articulation between teaching/research/EA is fundamental, anchored in interdisciplinary, educational, cultural, scientific and technological pedagogical processes. In 2021, this program had continuous activities, developed by the academic team linked to State University of Southwest Bahia (UESB), promoting oral health of children with microcephaly and their families.

In this project, extracurricular activities started in July 2020, in COVID-19 pandemic, offering online services of assistance and monitoring education in oral health. EA planned by the team consisted of guidance on topics such as cleaning teeth and tongue, gingival health and dental development through digital material, producing cards and videos for individuals with microcephaly and their respective families (Figure $1 \mathrm{~A}$ and $\mathrm{B})$. The chronology of tooth eruption caused the greatest digital interaction due to the constant participation of parents with children in the beginning of mixed dentition. The discussions generated by their questions provided a playful and scientific follow-up for everyone involved (Figure 2 A-D). The academic team realized the importance of online scientific activities on oral health in a more accessible language for this vulnerable population. 


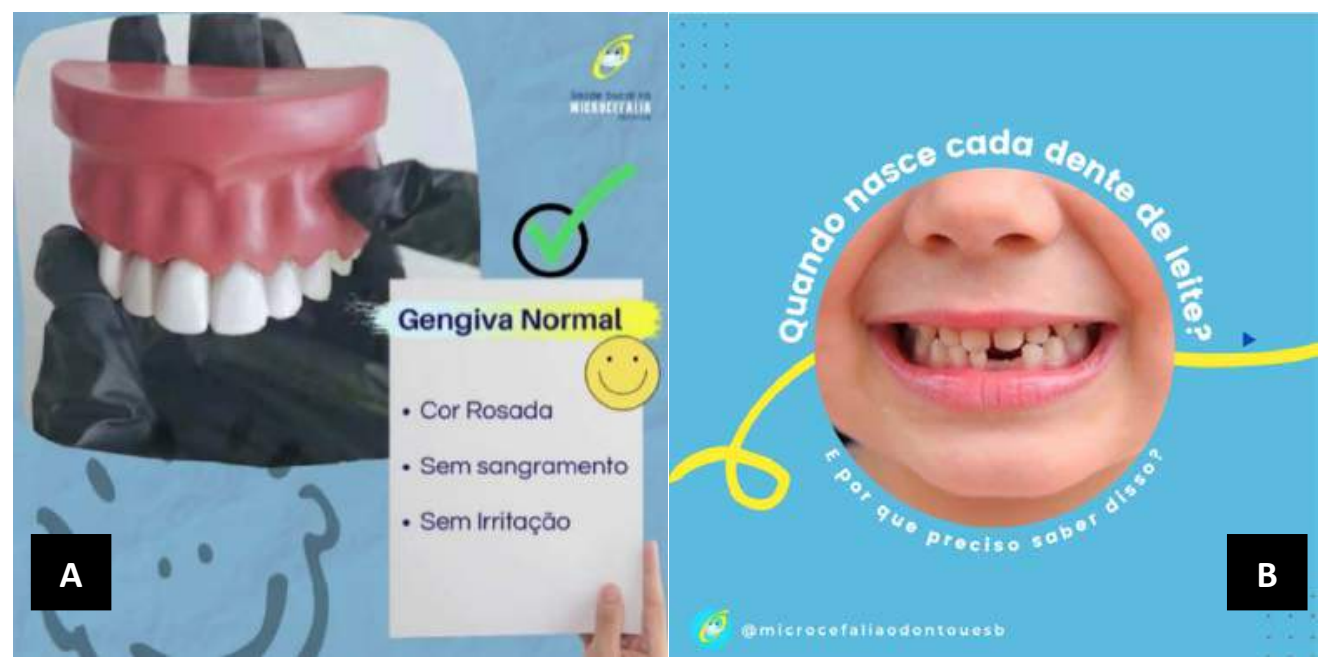

Figure 1: Video made by the project's students in a playful way about gingival health (A). Dental development card (B)

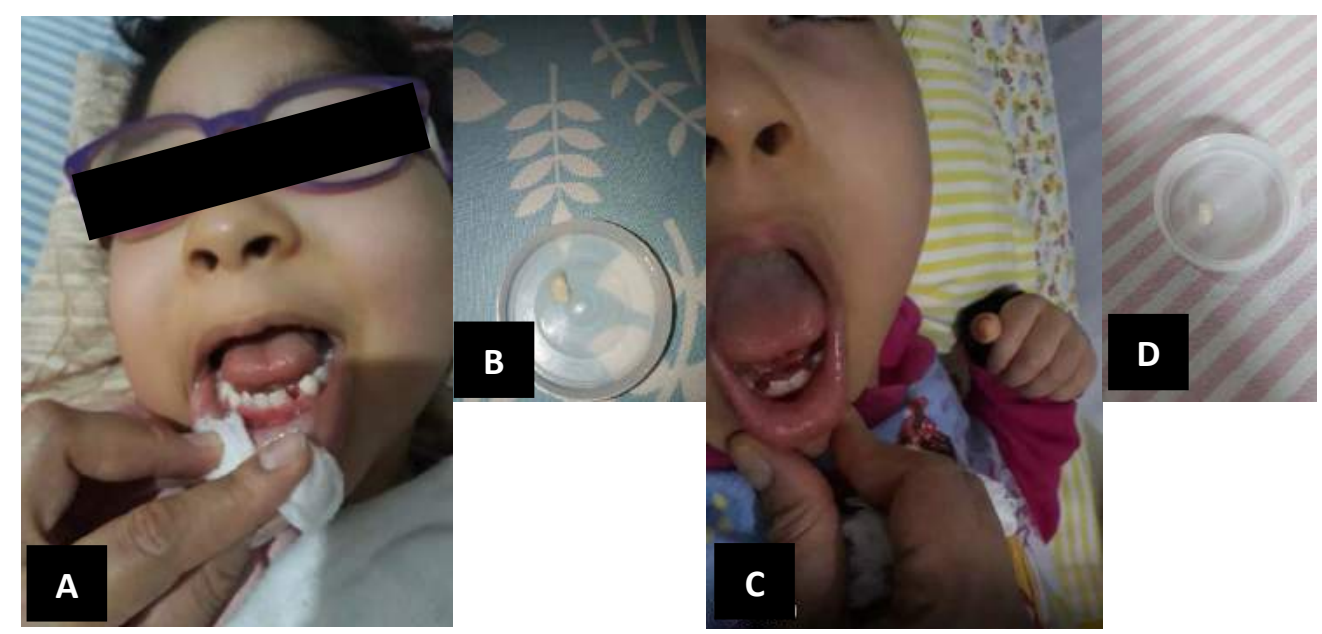

Figure 2: Digital resources provided by the mother of a child with microcephaly at the beginning of mixed dentition. Photograph shows her daughter's deciduous teeth loss (A-D)

One of the goals to obtain a differentiated academic formation is the humanized practice in public health services. In this context, after social isolation caused by COVID-19, clinical practices of dental care started assisting five children between five to eight years old with severe microcephaly, neuro psychomotor impairment, hearing and visual alterations. There were reports of medical stories after the pandemic period such as when one patient was diagnosed with Rett Syndrome and another with type I diabetes. A mother also reported that her child, with malnutrition, would have to use a naso-gastric tube. Parents of these patients related that they were using a pasty diet only during the day. There was also an increase in teeth grinding in the pandemic's isolation period. Concerning routine oral hygiene, three children had their teeth brushed once a day without tongue brushing. In two children who had their teeth brushed three times a day, the clinical management was easier. To enable dental examination and clinical procedures, these conditioning techniques were used: voice control, musical distraction, protective stabilization of neck, hands and feet performed by the parent and students. On intraoral examination, children were beginning the mixed dentition. Excessive salivation, atypical anterior lingual interposition and normal tooth development were observed. Two children were diagnosed with drug-induced fibrous gingival hyperplasia that causes tooth eruption anomalies. They were indicated for surgery planning. All patients and their parents, 
received a toothbrush and guidance about oral hygiene (Figure 3).

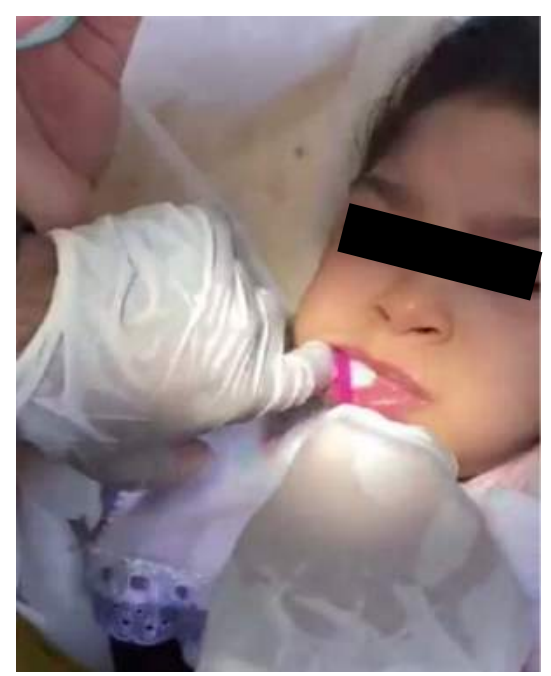

Figure 3: Clinical practice performed without physical stabilization on the patient with microcephaly in the mother's lap

The World Health Organization, an international reference on craniofacial anomalies, published a document entitled Global Strategies to reduce the Health-Care Burden of Craniofacial Anomalies. This document contained care protocol guidelines for this population, encompassing the need for oral health care for these patients (WHO, 2002). Children with microcephaly, in addition to the congenital anomaly due to the significant reduction in the occipitofrontal length when compared to those of the same sex and age, may present neuropsychomotor impairment (WHO, 2018). Studies report that these children are at greater risk of developing caries and periodontal disease (MARINHO et al, 2020). In the present deciduous molars. The treatment consisted of mechanical removal of dental calculus with topical application of $2 \%$ sodium fluoride (Figure 4 A-C). According to parents' reports, there was great anxiety for improving their children's oral health. Full attendance to clinical practice was a reality in all families, despite the financial and urban mobility difficulties. The student's perception about extracurricular activities trajectories follows reflection of Pietrovski et al. (2018), which evidences interaction in professional and social scope.

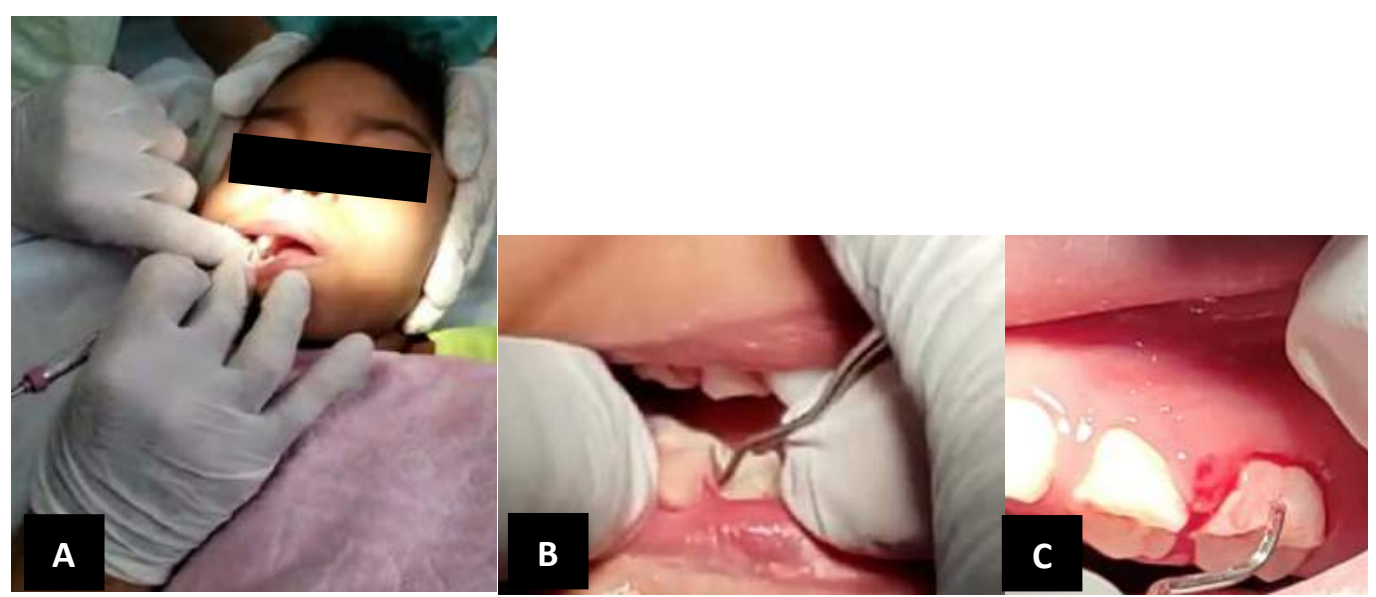

Figure 4: Dental care for a microcephaly patient. Beginning of dental calculus removal in deciduous molars (A-B). After the procedure (C) 
Religious and spiritual beliefs regulate individuals' emotions and can influence the acceptance of personal or loved ones' medical diagnosis and treatment (ABUCHAIM, 2018). In order to contribute to the mental health of parents with microcephaly children, the EA Nursing team promoted a virtual meeting to dialogue with mothers about spirituality and religiosity in their daily routine. There was also the participation of the EA Dentistry team. During reports of these solidary university education with greater patients' mothers, feelings such as faith, hope and love were perceived. This interdisciplinary link allowed students the opportunity of an ethical and understanding of the social dynamics in which they are inserted. In addition, the Nursing team contributed significantly to the development of cards and videos on preventive care against COVID-19 and the importance of vaccination (Figure $5 \mathrm{~A}-\mathrm{B}$ ), interacting with the students and the local community.
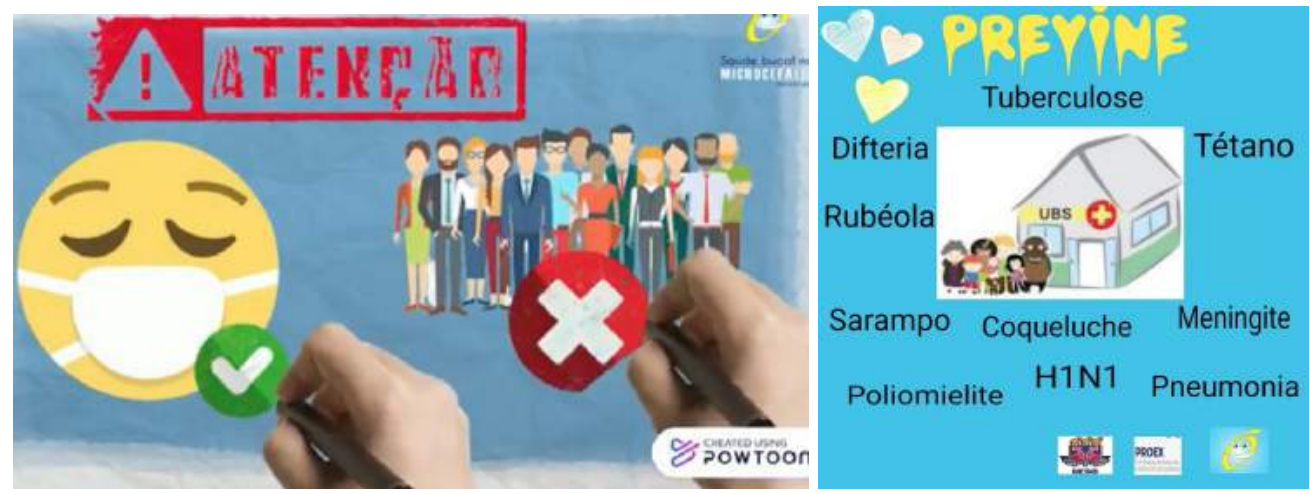

Figure 5: Videos about preventive care against COVID-19. Informational cards regarding vaccination importance

As for the relationship between teaching, research and extracurricular activities, the academic team showed that the EA deeply contributed to the improvement of their education. The integration of theory and practice enabled them to become professionals with social responsibility in the future. As for scientific knowledge, the EA consisted of weekly pedagogical meetings for six months by Google Meet to present seminars, discuss materials and information to be used in cards and videos. Also, there were discussions of what was prepared for the weekly exhibition, and experience reports about interaction with families (Figure 6). Scientific productions resulted in publishing of a paper and 2 abstracts in national events. One of these was awarded second place in an experience report academic fórum. As for the research, a project was started on the facial and dental characteristics of children with microcephaly. For the interdisciplinary relation with the nursing area, an important contribution of this practice can be observed in the public health services, resulting in enhanced pedagogical processes.

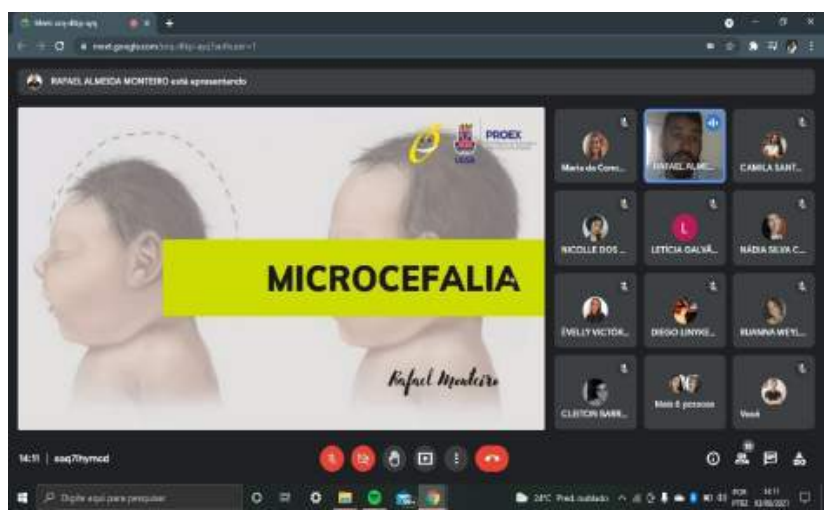

Figure 6: Seminar presentation present by a student for the academic community of UES 


\section{CONCLUSION}

After the social isolation period resulted from the COVID-19 pandemic, the return to clinical practices with the aim to offer oral health for children with microcephaly were enabled, without failing to provide online monitoring of preventive hygiene oral care. Parents' disbelief about the inclusion of their children in dental care must be overcomed by adopting preventive and interceptive procedures within public health services for individuals with microcephaly, in order to define a realistic prognosis and develop a health care protocol. The benefits arising from lessons, research and extracurricular activities provided a permanent link between the academic community and society.

\section{REFERÊNCIAS}

1. MINISTÉRIO DA EDUCAÇÃO DO BRASIL Resolução $\mathrm{N}^{\circ}$ 7, de 18 de dezembro de 2018. DIÁRIO OFICIAL DA UNIÃO. Disponível em https://www.in.gov.br/materia/-/asset_publi sher/KujrwoTZC2Mb/content/id/55877808 Acesso em 07 de novembro de 2021.

2. TEIXEIRA, C.N.G et al. Panorama situacional da Teleodontologia no mundo: uma revisão integrativa. Revista da Abeno, 2018; 18 (3): 24-34.

3. World Health Organization. (2002). Global strategies to reduce the health: Care burden of craniofacial anomalies. Geneva: WHO. Disponível em https://apps.who.int/iris/handle/10665/42594 Acesso em 07 de novembro de 2021.

4. World Health Organization. Microcephaly. 2018; Disponível em: https://www.who. int/ news-room/fact-sheets/detail/microcephaly. Acesso em 07 de setembro de 2021.

5. MARINHO et al. Aspectos clínicos da cavidade oral de pacientes com a síndrome congênita do Zica revisão de literatura. Diversitas Journal. 2020; 5(1): 57-65. doi:10.17648/div ersitas-journal-v5i1-932.

6. PIETROVSKI, E. F., BRONZERI, M. S., CUNHA, J. C., REIS, D. R., \& ALEGRE, L. M. P. A prática extracurricular activitiesa em uma universidade pública federal. Extensio:
Revista Eletrônica de Extensão. 2018;15(29): 2-19.

7. ABUCHAIM, S.C.B. Espiritualidade/religiosidade como recurso terapêutico na prática clínica: concepção dos estudantes de graduação em medicina da Escola Paulista de Medicina - Universidade Federal de São Paulo. 2018. 174f. Dissertação (Mestrado Profissional em Ensino em Ciências da Saúde) - Centro de Desenvolvimento do Ensino Superior em Saúde (CEDESS), Escola Paulista de Enfermagem, Universidade Federal de São Paulo, São Paulo, 2018. http://www2.unifesp. $\mathrm{br} /$ centros/cedess/mestrado/teses/tese_219_ silvia_abuchaim.pdf.

8. HOLANDA, L.A.L de et al. Teleodontologia, formação profissional e assistência odontológica no sistema único de saúde brasileiro: relato de experiência. Journal of Health. 2020; 1(24):1-17.

9. RIBEIRO E.O.A, WALTER C.C.F. Práticas de promoção de educação em saúde bucal para crianças com scz: uma reflexão. Facit Business And Technology Journal. ISSN: 2526-4281 http://revistas.faculdadefacit.edu.br/index.ph p/JNT. 2020; 30(1):184- 194.

Oral Health Promotion in Children With Microcephaly After Social Isolation by Covid-19: Experience Report 